CLINICAL STUDY

\title{
Growth hormone isoforms in newborns and postpartum women
}

\author{
Cesar L Boguszewski ${ }^{1,4}$, Margaret CS Boguszewski ${ }^{2}$, Francis de Zegher ${ }^{3}$, Björn Carlsson ${ }^{4}$ \\ and Lena MS Carlsson ${ }^{4}$ \\ ${ }^{1}$ SEMPR, Serviço de Endocrinologia e Metabologia do Hospital de Clínicas da Universidade Federal do Paraná, Curitiba, Brazil \\ ${ }^{2}$ UEP, Unidade de Endocrinologia Pediátrica do Hospital de Clínicas da Universidade Federal do Paraná, Curitiba, Brazil \\ ${ }^{3}$ Department of Pediatrics, University of Leuven, Leuven, Belgium \\ ${ }^{4}$ RCEM, Research Centre for Endocrinology and Metabolism, Department of Internal Medicine, University of Göteborg, Göteborg, Sweden \\ (Correspondence should be addressed to CL Boguszewski, SEMPR-Serviço de Endocrinologia e Metabologia do Hospital de Clínicas da Universidade \\ Federal do Paraná, Rua Padre Camargo, 262 Curitiba, PR, Brazil CEP: 80060-240; Email: cesarlui@hc.ufpr.br; clbogus@mandic.com.br)
}

\begin{abstract}
The neonatal and postpartum periods are characterized by alterations in pituitary GH secretion. We have investigated the proportion of circulating non- $22 \mathrm{kDa} G H$ isoforms in newborns, in women within the early postpartum phase (just after the disappearance of placental GH from the maternal circulation) and in women during late postpartum (during the somatotroph recovery phase). We studied 10 newborns ( 7 males; 3 females; median postnatal age, $45 \mathrm{~h}$ ), who had been admitted because of polycythaemia, 10 women in the early postpartum phase (median, $48 \mathrm{~h}$ after delivery; range, 42-54 h), 18 women in the late postpartum phase (median, 10 weeks after delivery; range, 325 weeks) and 9 healthy non-pregnant women. The proportion of non- $22 \mathrm{kDa}$ GH isoforms was determined by the $22 \mathrm{kDa} \mathrm{GH}$ exclusion assay, which is based on immunomagnetic extraction of $22 \mathrm{kDa} \mathrm{GH}$ from serum, and quantitation of non- $22 \mathrm{kDa}$ GH isoforms using a polyclonal GH assay. In newborns, non-22 kDa GH isoforms were measured in two arterial blood samples obtained with a 5$6 \mathrm{~h}$ interval. In the other groups, serum samples were obtained $40 \mathrm{~min}$ after an i.v. bolus administration of the GH secretagogue, GH releasing peptide-1 (GHRP-1).

In newborns, the median proportion of non-22 kDa GH isoforms was $10 \%$ (range, $7.2-19.4 \%$ ) and the values were similar in samples collected at different times. In early postpartum women, total GH levels after GHRP-1 were lower and the proportion of non- $22 \mathrm{kDa}$ GH isoforms was higher compared with the values in non-pregnant and late-postpartum women. In late postpartum, there was a partial recovery of GH response to GHRP-1, as shown by an increment in total GH levels, which was associated with a decrease in the fraction of non- $22 \mathrm{kDa} \mathrm{GH}$ isoforms.

In conclusion, we found that (i) the proportion of non- $22 \mathrm{kDa} \mathrm{GH}$ isoforms in the newborn is comparable to that in the adult (non-pregnant women), (ii) in early postpartum, the non- $22 \mathrm{kDa}$ fraction is high within the small pool of readily releasable GH, (iii) in late postpartum, recovery of pituitary $\mathrm{GH}$ responsiveness is associated with a relative decrease in the release of non- $22 \mathrm{kDa} \mathrm{GH}$ isoforms.
\end{abstract}

European Journal of Endocrinology 142 353-358

\section{Introduction}

Human growth hormone $(\mathrm{GH})$ consists of a complex mixture of several structurally modified isoforms and fragments that have been detected in blood, pituitary extracts and placenta (for reviews, see 1-3), in addition to the main 22 kilodalton ( $\mathrm{kDa}) \mathrm{GH}$. The presence of circulating non-22 kDa GH isoforms and fragments contributes to the discrepancies in GH measurements, since the free monomeric $22 \mathrm{kDa} \mathrm{GH}$ accounts for only about $25 \%$ of the GH immunoreactivity in serum (2). The physiological role of multiple GH isoforms is not clear, but this mixture of molecules may intermodulate their activities by acting as partial agonist or antagonists of the GH receptor (3-5). In addition, it has been suggested that some $\mathrm{GH}$ isoforms might act through specific receptors $(3,6,7)$.

The GH heterogeneity arises from different sources, one of which is the presence of two related genes in the human GH gene cluster with tissue-specific expression: the GH-N gene in the anterior pituitary and the GH-V gene in the placenta $(8-10)$. The pituitary secretion of $\mathrm{GH}$ is pulsatile and regulated mainly by two hypothalamic peptides, GH-releasing hormone (GHRH) 
and somatostatin (SRIH). During pregnancy, the pulsatile release of $\mathrm{GH}$ from the pituitary is progressively suppressed and replaced by a continuous secretion of placental GH into the maternal circulation (11-14). Consequently, the somatotrophs are less responsive to GH secretagogues, such as GHRH, in the early postpartum phase, with a gradual recovery of pituitary $\mathrm{GH}$ secretion observed at the late postpartum phase (15-17).

In the fetus, circulating $\mathrm{GH}$ levels fall towards the end of gestation, while there is an amplification of $\mathrm{GH}$ secretion immediately after birth $(18,19)$. Accordingly, the neonatal period is characterized by a physiological hypersecretion of $\mathrm{GH}$. Using a panel of site-specific monoclonal antibodies, King et al. (20) found that 30 to $60 \%$ of the circulating $\mathrm{GH}$ during the first three months of life represents the $20 \mathrm{kDa} \mathrm{GH}$, an isoform produced by the use of an alternative splice site within exon 3 of the GH-N (21) and GH-V gene (9). However, this finding has not been confirmed by recent studies where $20 \mathrm{kDa} \mathrm{GH}$ was measured by specific ELISA and showed a lower proportion of this isoform in cord blood and in serum samples collected at early postnatal life $(22,23)$.

We have developed the $22 \mathrm{kDa} \mathrm{GH}$ exclusion assay (GHEA), in which the $22 \mathrm{kDa} \mathrm{GH}$ isoform is extracted from serum and the levels of non-22 kDa GH isoforms, which include $20 \mathrm{kDa} \mathrm{GH}$ and other immunoreactive isoforms, fragments and oligomers of $\mathrm{GH}$, are quantitated (24). The GHEA has been conceived as a screening method for application in a large number of clinical samples, allowing the identification of an abnormal proportion of non-22 kDa GH isoforms in different physiological and pathological conditions.

In the present study, we have applied the GHEA to evaluate the proportion of circulating non- $22 \mathrm{kDa} G \mathrm{GH}$ isoforms in periods of life characterized by alterations in pituitary GH secretion: (i) the neonatal period, when there is a physiological hypersecretion of $\mathrm{GH}$; (ii) the early postpartum phase, just after the disappearance of placental GH from the maternal circulation; and (iii) the late postpartum phase, when somatotroph function seems to recover.

\section{Subjects and methods}

\section{Neonatal samples}

Ten newborns ( 7 males and 3 females), who had been admitted to the neonatal care unit because of symptoms related to polycythaemia, were studied as previously reported (19). None of the newborns was in severe distress. The range of the gestational ages was 32 to 38 weeks (median, 37.5 weeks), of postnatal ages 3 to $95 \mathrm{~h}$ (median, $45 \mathrm{~h}$ ), and of birthweight 1030 to $2490 \mathrm{~g}$ (median, $2100 \mathrm{~g}$ ). Blood samples ( $1 \mathrm{ml} / \mathrm{kg}$ ) were obtained every $20 \mathrm{~min}$ for $6 \mathrm{~h}$ through an umbilical or peripheral arterial catheter during a standardized partial exchange transfusion. During the procedure, the infants received an isotonic plasma protein solution and continuous $10 \%$ glucose infusion. They were not fed, but were allowed nonnutritive suckling.

Blood was collected into glass tubes; after clotting at $4^{\circ} \mathrm{C}$ and centrifugation, the serum was kept frozen at $-20{ }^{\circ} \mathrm{C}$ until analysis. The total $\mathrm{GH}$ and non- $22 \mathrm{kDa}$ $\mathrm{GH}$ concentrations were measured by the GHEA in two distinct stored samples from the same infant, one collected at the start of the partial exchange transfusion (sample A) and the other collected after a 5-6 h interval (sample B). All samples were assessed in the same assay run. As blood samples were obtained during a therapeutic procedure and would otherwise have been discarded, the study protocol was not submitted for institutional review and parental consent was not requested.

\section{Maternal samples}

A total of 37 women, age range $24-40$ years, was studied. The control group consisted of healthy nonpregnant women $(n=9)$, who were either in the late follicular stage of a spontaneous cycle or between days 11 and 21 of a cycle timed by low dose oestrogen/ progestagen contraceptive medication at the time of the study. The study groups consisted of lactating women $(n=10)$ in the early postpartum phase (median, $48 \mathrm{~h}$ after delivery; range, $42-54 \mathrm{~h}$ ), and lactating and nonlactating women $(n=18)$ in the late postpartum phase (median, 10 weeks after delivery; range, 3-25 weeks).

The samples were obtained as previously described (17). Briefly, an indwelling venous catheter was inserted approximately $20 \mathrm{~min}$ before the start of the sampling. Blood was collected every $20 \mathrm{~min}$, from 20 min before until 100 min after an i.v. bolus administration of $100 \mu \mathrm{g}$ GH releasing peptide-1 (GHRP-1) (Ala-His-D $\beta$-Nal-Ala-D-Trp-Phe-Lys- $\mathrm{NH}_{2}$ ), which was provided by Dr CY Bowers. All studies were started between 08.00 and $10.00 \mathrm{~h}$, at least $2 \mathrm{~h}$ after a light breakfast. In the groups of lactating mothers, the last breastfeeding before the study was initiated approximately $90 \mathrm{~min}( \pm 30 \mathrm{~min}$ ) before bolus injection.

The total $\mathrm{GH}$ and non-22 $\mathrm{kDa} \mathrm{GH}$ concentrations were measured in stored samples collected $40 \mathrm{~min}$ after GHRP-1 administration, representing the samples obtained at or just after the occurrence of the GH peak. All samples were assessed in the same assay run. The study protocol was approved by the Ethics Committee of the University of Leuven Medical School and all subjects gave their informed consent.

\section{GH exclusion assay (GHEA)}

The $22 \mathrm{kDa}$ GHEA, which has been described previously, is an immunomagnetic extraction-based assay for serum measurement of non-22 kDa GH isoforms (24). 
Briefly, a $100 \mu \mathrm{l}$ aliquot of serum is incubated with an anti-22 kDa GH monoclonal antibody (MCB, Genentech Inc., South San Francisco, CA, USA). Paramagnetic beads coated with rat anti-mouse immunoglobulin G, and a magnet device (Dynal, Oslo, Norway) are used to remove monomeric and dimeric $22 \mathrm{kDa} \mathrm{GH}$ from serum. After extraction, the non- $22 \mathrm{kDa}$ GH levels are measured by a polyclonal antibody-based GH-IRMA (Pharmacia \& Upjohn, Uppsala, Sweden). In the GHEA, total $\mathrm{GH}$ concentrations are determined in another $100 \mu \mathrm{l}$ aliquot of serum incubated only with assay buffer (without the addition of the MCB), and non$22 \mathrm{kDa} \mathrm{GH}$ levels are expressed as a percentage of total GH in the samples. There is no influence of storage, freezing and thawing of the samples in the measurements of non-22 kDa GH levels by the GHEA (24).

\section{Statistical analysis}

All the descriptive statistical results are presented as the median and range. Comparisons between groups were carried out using the Mann-Whitney U-test. Correlations were sought by calculating the Spearman rank correlation coefficient. A $P$ value less than 0.05 was considered significant.

\section{Results}

\section{Neonatal samples}

The median total $\mathrm{GH}$ concentrations in neonatal samples $\mathrm{A}$ and $\mathrm{B}$ were $13.5 \mu \mathrm{g} / \mathrm{l}$ (range, 3.7 to $68.1 \mu \mathrm{g} / \mathrm{l}$ ) and $13.7 \mu \mathrm{g} / \mathrm{l}$ (range, 4.7 to $50.0 \mu \mathrm{g} / \mathrm{l}$ ) respectively, with a median proportion of non- $22 \mathrm{kDa}$ $\mathrm{GH}$ isoforms in sample A of $9.7 \%$ (range, 7.2 to $19.4 \%$ ) and in sample $\mathrm{B}$ of $10.5 \%$ (range, 7.5 to $16.3 \%$ ) (Table 1). The overall median proportion of non-22 kDa

Table 1 Total GH concentrations and proportion of non-22 kDa $\mathrm{GH}$ isoforms measured by the $22 \mathrm{kDa}$ GHEA in two arterial samples of the same newborn collected with a 5-6h interval during a therapeutic transfusion.

\begin{tabular}{lccccc}
\hline & \multicolumn{2}{c}{ Total GH $(\mu \mathrm{g} / \mathrm{l})$} & & \multicolumn{2}{c}{ Non-22 kDa GH (\%) } \\
\cline { 2 - 3 } \cline { 5 - 6 } Newborn & Sample A & Sample B & & Sample A & Sample B \\
\cline { 5 - 6 } 1 & 8.6 & 5.8 & & 9.2 & 9.1 \\
2 & 44.2 & 13.5 & & 17.8 & 16.3 \\
3 & 55.2 & 30.0 & & 7.2 & 12.3 \\
4 & 8.0 & 20.5 & & 19.4 & 11.6 \\
5 & 13.5 & 13.9 & & 11.0 & 8.4 \\
6 & 68.1 & 10.0 & & 8.9 & 10.6 \\
7 & 26.3 & 50.0 & & 11.7 & 12.6 \\
8 & 12.7 & 9.7 & & 9.4 & 7.5 \\
9 & 3.7 & 4.7 & & 7.2 & 7.8 \\
10 & 24.3 & 22.7 & & 9.9 & 10.3 \\
Median & 13.5 & 13.7 & & 9.7 & 10.5 \\
\hline
\end{tabular}

GH isoforms in all neonatal samples $(n=20)$ was $10.1 \%$. The percentage of non-22 kDa GH isoforms was fairly stable in the two samples of the same newborn collected at different times, with a median intra-individual variation of $1.6 \%$ (range, 0.1 to $7.8 \%$ ), whereas the median intra-individual variation of total $\mathrm{GH}$ levels was $7.8 \mu \mathrm{g} / \mathrm{l}$ (range, 0.4 to $58.1 \mu \mathrm{g} / \mathrm{l}$ ).

\section{Maternal samples}

Figure 1 depicts total GH concentrations and the percentage of non- $22 \mathrm{kDa} \mathrm{GH}$ isoforms in the three study groups. In the control group of non-pregnant women, the median total $\mathrm{GH}$ concentration after GHRP-1 administration was $49.5 \mu \mathrm{g} / \mathrm{l}$ (range, 17.5 to $77.3 \mu \mathrm{g} / \mathrm{l}$ ) and the median proportion of non- $22 \mathrm{kDa}$ $\mathrm{GH}$ isoforms was $10.7 \%$ (range, 7.9 to $11.1 \%$ ). In postpartum women, there was an opposite pattern of total GH and non-22 kDa GH isoforms in the circulation during early and late phases. The pituitary was less responsive to the $\mathrm{GH}$ secretagogue at the early postpartum phase, as shown by significantly lower median total GH concentrations after GHRP-1 stimulation in this group (median $8.6 \mu \mathrm{g} / \mathrm{l}$; range, 2.7 to $25.7 \mu \mathrm{g} / \mathrm{l})$, compared with that in non-pregnant women $(P<0.001)$. At the late postpartum period, the pituitary GH secretion after GHRP-1 was partly recovered, with the median total $\mathrm{GH}$ concentration higher than that in the early postpartum phase (median $19.2 \mu \mathrm{g} / \mathrm{l}$; range, 4.6 to $81.0 \mu \mathrm{g} / \mathrm{l} ; P=0.01$ ), but still significantly lower than the median value seen in the control group $(P=0.02)$.

In contrast to the total $\mathrm{GH}$ concentration, the median proportion of non-22 kDa GH isoforms after GHRP-1 was significantly higher at the early postpartum phase (median $14.2 \%$; range 8.7 to $18.2 \%$ ) compared with the percentage in non-pregnant women $(P=0.003)$. At the late postpartum phase, the median proportion of non-22 kDa GH isoforms after GHRP-1 was $8.1 \%$ (range, 4.3 to $11.9 \%$ ), which was significantly lower than the value in the control group $(P<0.01)$ and in the early postpartum phase $(P<0.01)$.

\section{Discussion}

The pituitary secretion of GH in newborns is intermittent and distinctly pulsatile, indicating that the regulatory system of GHRH and SRIH is operational by the first day of postnatal life. A characteristic finding of the immediate postnatal period is that plasma concentrations of $\mathrm{GH}$ are markedly elevated (19). This elevation could be explained by several factors, including a higher sensitivity of somatotrophs to GHRH than to SRIH, an amplifying effect on GH secretion caused by oestrogens of placental origin or by a neonatal surge in thyroid hormones, a fall in serum levels of insulinlike growth factor-I within hours after birth, and a physiological decrease in nutrient supply $(19,25,26)$. 

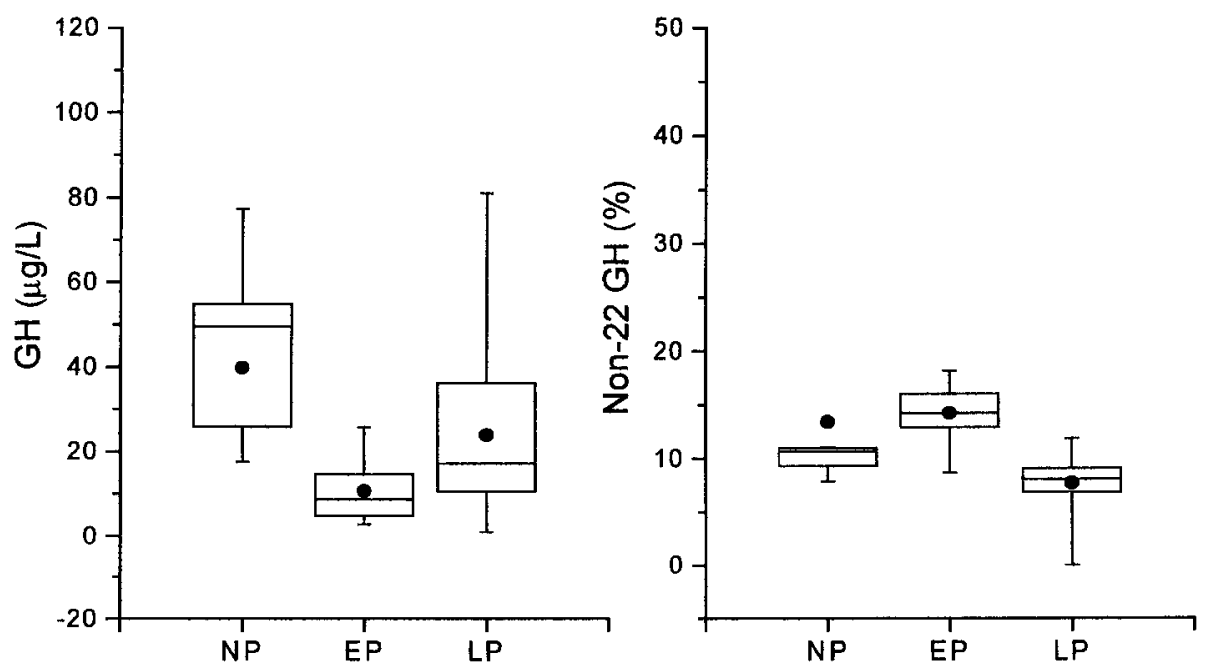

Figure 1 Total GH concentrations (left panel) and the proportion of non- $22 \mathrm{kDa}$ GH isoforms (right panel), as measured by the $22 \mathrm{kDa}$ GHEA, in 9 non-pregnant women (NP), 10 early postpartum women (EP) and 18 late-postpartum women (LP). The GHEA was applied to samples collected $40 \mathrm{~min}$ after administration of an i.v. bolus of GHRP-1. The box-and-whisker plots indicate median, lower and upper quartiles and the whiskers indicate the 1 st and 99th percentiles. The mean values are depicted as solid circles in each box plot. In the left panel, $P<0.001 \mathrm{EP}$ vs NP, $P=0.01 \mathrm{EP}$ vs LP, and $P=0.02 \mathrm{LP}$ vs NP; in the right panel, $P=0.003 \mathrm{EP}$ vs NP, $P<0.01 \mathrm{LP}$ vs EP and $P<0.01$ LP vs NP.

The neonatal hypersomatotrophism is not due to a decreased clearance of $\mathrm{GH}$, since the half-life of $\mathrm{GH}$ in the newborn has been shown to be around $18 \mathrm{~min}$, identical to that in children and adults (19). It is known that $20 \mathrm{kDa} \mathrm{GH}$ and oligomeric forms of $\mathrm{GH}$ are cleared more slowly from blood than is $22 \mathrm{kDa} \mathrm{GH}$ $(27,28)$. Thus, one would expect a prolonged half-life of circulating $\mathrm{GH}$ in newborns if the proportion of $20 \mathrm{kDa}$ GH isoforms was as high as $60 \%$ of total GH, as previously reported (20). Our results showed that hypersecretion of $\mathrm{GH}$ in polycythaemic newborns was not associated with increased amounts of non- $22 \mathrm{kDa}$ $\mathrm{GH}$ isoforms, which represented in the present study $10 \%$ of the total $\mathrm{GH}$ in the circulation. Although the newborns in the present study were not completely healthy, our results are in accordance with two other recent studies where only $20 \mathrm{kDa} \mathrm{GH}$ was measured by a direct ELISA in cord blood samples and samples collected from preterm and full-term neonates, showing a mean percentage of $20 \mathrm{kDa} \mathrm{GH}$ varying from 2.7 to $10.3 \%$ of total circulating GH $(22,23)$. The fraction of non-22 kDa GH isoforms in our newborns was similar to that in our group of non-pregnant women, despite marked differences in total GH concentrations between the groups. In addition, the neonatal values were also comparable to those reported by us in a group of healthy children at different stages of puberty (29). Hence, the normal proportion of circulating non- $22 \mathrm{kDa} \mathrm{GH}$ isoforms in our study is in agreement with the previously reported half-life of GH in newborns (19). However, higher amounts of non-22 kDa GH isoforms may be present in the circulation of newborns in some circumstances, as it has been shown that serum $20 \mathrm{kDa} G H$ levels are increased in cord blood of neonates with low birth weight (22).

During pregnancy, serum levels of placental GH rise in association with a fall in serum GH levels of pituitary origin $(11,30)$. The physiological postpartum phases are characterized by the gradual return of the pulsatile pituitary GH secretion. At early postpartum, the somatotrophs are less responsive to GHRH, with some recovery seen at the late postpartum phase (16). The present study has shown that the same pattern of $\mathrm{GH}$ hyporesponsiveness is found in postpartum women through the GHRP pathway. Interestingly, non-22 kDa $\mathrm{GH}$ isoforms were present in increased proportion in the early postpartum period, when somatotrophs were less responsive to GHRP-1 and total GH levels were low. At the late postpartum period, the opposite was found, with a partial recovery of the somatotrophic response leading to an elevation of total $\mathrm{GH}$ concentrations associated with a lower fraction of non- $22 \mathrm{kDa} G H$ isoforms in the circulation. It has been demonstrated that suppression of pituitary GH synthesis during gestation is associated with a reduced number of $\mathrm{GH}$ immunoreactive cells in the adenohypophysis, which are, in turn, less abundant in $\mathrm{GH}$ messenger ribonucleic acid (31). These observations indicate that the somatotrophs are not fully recovered during the first days after delivery, and that their low GH secretory capacity is associated with increased production of non- $22 \mathrm{kDa} \mathrm{GH}$ isoforms. At late postpartum, there is a tendency towards normalization of pituitary $\mathrm{GH}$ secretion, not only in terms of responsiveness of the somatotrophs to GHRP-1, but also regarding the ratio of $\mathrm{GH}$ isoforms secreted by the gland. In fact, the 
recovery of pituitary secretion during the late postpartum stage is characterized by a marked decrease in the pituitary release of non- $22 \mathrm{kDa} \mathrm{GH}$ isoforms and an enhanced production of the predominant $22 \mathrm{kDa}$ GH. Although it is not clear at this moment if this distinct GH secretory pattern has physiological significance in postpartum women, there are previous in vitro and in vivo studies showing that $\mathrm{GH}$ and its isoforms have different binding affinities to somatogenic and lactogenic receptors and that $\mathrm{GH}$ might exert some influence on human lactation (32-35).

\section{Acknowledgements}

The authors are grateful to the Genentech Inc. for the gift of the MCB monoclonal antibody, to Dr CY Bowers (Tulane University, New Orleans, USA) for the generous gift of GHRP-1, to the Staff of the Neonatal Intensive Care Unit and the Postpartum Ward of the University Hospital Gasthuisberg (Leuven) for their co-operation in the organization of the study, to Danielle Lemmens, RN and Karin Vanweser, RN (Leuven) for sample collection and editorial support, and to Ulla Karlsson (Göteborg) for technical assistance. This work was supported by grants from the Swedish Medical Research Society ( $\left.\mathrm{N}^{\mathrm{o}} 11285,11502,13141\right)$. Francis de Zegher is a Clinical Research Investigator of the Fund for Scientific Research, Flanders, Belgium.

\section{References}

1 Lewis UJ. Growth hormone: what is it and what does it do? Trends in Endocrinology and Metabolism 19923 117-121.

2 Baumann G. Growth hormone heterogeneity in human pituitary and plasma. Hormone Research 199951 (Suppl 1) 2-6.

3 Goffin V, Shiverick K, Kelly PA \& Martial JA. Sequence-function relationships within the expanding family of prolactin, growth hormone, placental lactogen, and related proteins in mammals. Endocrine Reviews 199617 385-410.

4 de Vos AM, Ultsch M \& Kossiakoff AA. Human growth hormone and extracellular domain of its receptor: crystal structure of the complex. Science $1992255306-312$.

5 Fuh G, Cunningham BC, Fukunaga R, Nagata S, Goeddel DV \& Wells JA. Rational design of potential antagonists to the human growth hormone receptor. Science 1992256 1677-1680.

6 Baumann G \& Shaw MA. Plasma transport of the 20000 -dalton variant of human growth hormone $(20 \mathrm{~K})$ : evidence for a 20 K-specific binding site. Journal of Clinical Endocrinology and Metabolism 199071 1339-1343.

7 Rowlinson SW, Walters MJ, Lewis UJ \& Barnard R. Human growth hormone fragments $1-43$ and 44-191: in vitro somatogenic activity and receptor binding characteristics in human and nonprimate systems. Endocrinology 1996137 90-95.

8 Cooke NE, Ray J. Watson MA, Estes PA, Kuo BA \& Liebhaber AS. Human growth hormone gene and the highly homologous growth hormone variant gene display different splicing patterns. Journal of Clinical Investigation 198882 270-275.

9 Boguszewski CL, Svensson P-A, Jansson T, Clark R, Carlsson LMS \& Carlsson B. Cloning of two novel growth hormone transcripts expressed in human placenta. Journal of Clinical Endocrinology and Metabolism 199883 2878-2885.

10 Seeburg PH. The human growth hormone gene family: nucleotide sequences show recent divergence and predict a new polypeptide hormone. DNA 19821 239-249.
11 Hennen G, Frankenne F, Closset J, Gomez F, Pirens G \& El Khayat N. A human placental GH: increasing levels during second half of pregnancy with pituitary GH suppression as revealed by monoclonal antibody radioimmunoassays. International Journal of Fertility 198530 27-33.

12 Frankenne F, Closset J, Gomez F, Scippo ML, Smal J \& Hennen G. The physiology of growth hormones in pregnant women and partial characterization of the placental GH variant. Journal of Clinical Endocrinology and Metabolism 198866 1171-1180.

13 Ericksson L, Frankenne F, Edèn S, Hennen G \& Von Schoultz B. Growth hormone 24-h serum profiles during pregnancy - lack of pulsatility for the secretion of the placental variant. British Journal of Obstetrics and Gynaecology 198996 949-953.

14 de Zegher F, Vanderschueren-Lodeweyckx M, Spitz B, Faijerson Y, Blomberg F, Beckers A et al. Perinatal growth hormone $(\mathrm{GH})$ physiology: effect of GH-releasing factor on maternal and fetal secretion of pituitary and placental GH. Journal of Clinical Endocrinology and Metabolism 199071 520-522.

15 Spellacy WN \& Buhi WC. Pituitary GH and PL levels measured in normal term pregnancy and at the early and late postpartum periods. American Journal of Obstetrics and Gynecology 196915 888-896.

16 de Leo V, Lanzetta D, d'Antona D, Latessa AM \& Petraglia F. Control of growth hormone secretion during the postpartum period. Gynecology and Obstetrics Investigation 199233 31-35.

17 de Zegher F, Spitz B, Van Den Berghe G, Lemmens D, Vanweser K, Keppens $\mathrm{K}$ et al. Postpartum hyperprolactinemia and hyporesponsiveness of growth hormone $(\mathrm{GH})$ to GH-releasing peptide. Journal of Clinical Endocrinology and Metabolism $1998 \mathbf{8 3}$ 103-106.

18 Kaplan SL, Grumbach MM \& Aubert ML. The ontogenesis of pituitary hormones and hypothalamic factors in the human fetus: maturation of central nervous system regulation of anterior pituitary function. Recent Progress in Hormone Research 197632 $161-243$.

19 de Zegher F, Devlieger H \& Veldhuis JD. Properties of growth hormone and prolactin hypersecretion by the human infant on the day of birth. Journal of Clinical Endocrinology and Metabolism 199376 1177-1181.

20 King KC, Chasalow F, Faklis EJ \& Blethen SL. Postnatal changes in growth hormone isoforms in preterm and term infants. Endocrinology and Metabolism 19941 (Suppl B) 3.

21 Lewis UJ, Bonewald LF \& Lewis LJ. The 20000 -dalton variant of human growth hormone: location of the amino acid deletions. Biochemical and Biophysical Research Communications 198092 511-516.

22 Pringle PJ, Geary MPP, Hindmarsh PC, Brook CGD \& Robinson ICAF. Variants of human growth hormone in cord blood correlate with birth weight. Proceedings of the 81st Annual Meeting of the Endocrine Society, San Diego, CA, USA, 1999, p 111.

23 Bozzola M, Pagani S, Avanzini MA, Belloni C, Messner H, Autelli M, Comoli P \& Radetti G. Variations of growth hormone $(\mathrm{GH})$ isoforms during the early postnatal life. Hormone Research 199951 (Suppl 2) 26.

24 Boguszewski CL, Hynsjö L, Johannsson G, Bengtsson B-A \& Carlsson LMS. 22-kDa Growth hormone exclusion assay: a new approach to measurement of non-22-kDa growth hormone isoforms in human blood. European Journal of Endocrinology 1996135 573-582.

25 Fischer DA \& Polk DH. Development of the thyroid. Bailliere's Clinical Endocrinology and Metabolism 19893 627-657.

26 Mauras N, Rogol AD \& Veldhuis JD. Increased hGH production rate after low-dose estrogen therapy in prepubertal girls with Turner's syndrome. Pediatric Research 199028 626-630.

27 Baumann G, Stolar MW \& Buchanan TA. Slow metabolic clearance of the 20000-dalton variant of human growth hormone: implications for biological activity. Endocrinology $19851171309-1313$.

28 Hendricks CM, Eastman RC, Takeda S, Asakawa K \& Gordon P. Plasma clearance of intravenously administered pituitary human 
growth hormone: gel filtration studies of heterogeneous components. Journal of Clinical Endocrinology and Metabolism 198560 864-867.

29 Boguszewski CL, Jansson C, Boguszewski MCS, Rosberg S, Albertsson-Wikland K, Carlsson B et al. Circulating non-22-kDa growth hormone isoforms in healthy children of normal stature: relation to height, body mass and pubertal development. European Journal of Endocrinology 1997137 246-253.

30 Kelly PA, Djiane J, Postel-Vinay MC \& Edery M. The prolactin/ growth hormone receptor family. Endocrine Reviews 199112 235-251.

31 Stefaneanu L, Kovacs K, Lloyd RV, Scheithauer BW, Young WF Jr, Sano $\mathrm{T}$ et al. Pituitary lactotrophs and somatotrophs in pregnancy: a correlative in situ hybridization and immunocytochemical study. Virchows Archiv 199262 291-296.

32 Haro LS, Singh RN, Lewis UJ, Martinez AO, Galosy SS, Staten NR et al. Human growth hormone deletion mutant (hGH44-191) binds with high affinity to lactogenic receptors but not to somatogenic receptors. Biochemical and Biophysical Research Communications 1996222 421-426.

33 Wada M, Tsunekawa B, Ikeda M \& Honjo M. The weak effect of $20 \mathrm{~K}$ human growth hormone on stimulation of JAK 2/STAT 5 signaling pathway via human prolactin receptor. Proceedings of the 80th Annual Meeting of the Endocrine Society, New Orleans, LA, USA, 1998, p 301.

34 Milson SR, Breier BH, Gallaher BW, Cox VA, Gunn AJ \& Gluckman PD. Growth hormone stimulates galactopoiesis in healthy lactating women. Acta Endocrinologica 1992127 337-343.

35 Milson SR, Rabone DL, Gunn AJ \& Gluckman PD. Potential role for growth hormone in human lactation insufficiency. Hormone Research 199850 147-150.

Received 6 July 1999

Accepted 13 December 1999 